\begin{tabular}{|c|l|}
\hline Title & $\begin{array}{l}\text { Development of an anatomical technique for visualizing the mode of climbing fiber innervation in Purkinje cells and its } \\
\text { application to mutant mice lacking GluR } 2 \text { and Cav2.1 }\end{array}$ \\
\hline Author(s) & Miyazaki, Taisuke; W atanabe, Masahiko \\
\hline Citation & $\begin{array}{l}\text { A natomical Science International, 86/1), 10-18 } \\
\text { https://doi.org/10.1007/312565-010-0095-1 }\end{array}$ \\
\hline Issue Date & 2011-03 \\
\hline Doc URL & http://hdl.handle.net/2115/47272 \\
\hline Rights & The original publication is available at www.springerlink.com \\
\hline Type & article (author version) \\
\hline File Information & A SI86-1_10-18.pdf \\
\hline
\end{tabular}

Instructions for use 


\section{Development of anatomical technique visualizing the mode of climbing fiber innervation in Purkinje cells and its application to mutant mice lacking GluRס2 and $\mathrm{Ca}_{\mathrm{v}} 2.1$}

Taisuke Miyazaki, Masahiko Watanabe

Department of Anatomy, Hokkaido University Graduate School of Medicine, Sapporo 060-8638, Japan.

Short running title: Tracer/VGluT2 labeling of CF innervation

24 Text Pages, 5 Figures,

Number of words: Abstract, 235

Corresponding author: Masahiko Watanabe

Department of Anatomy, Hokkaido University School of Medicine, Sapporo 060-8638, Japan. TEL: +81-11-706-5032; FAX: +81-11-706-5031; e-mail: watamasa@med.hokudai.ac.jp

Key Words (Five words): Purkinje cell, climbing fiber, cerebellum, anterograde tracer labeling, type 2 vesicular glutamate transporter

\section{Acknowledgments}

This study was supported through Special Coordination Funds for promoting Science and Technology, Grants-in-Aid for Scientific Research (19100005 to MW) provided by the Ministry of Education, Culture, Sports, Science and Technology of Japan. 


\section{Abstract}

In the adult cerebellum, a single climbing fiber (CF) innervates proximal dendrites of Purkinje cells (PCs). This mono-innervation is established by developmental elimination of surplus CFs through homosynaptic competition among multiply-innervating CFs and heterosynaptic competition between CFs and parallel fibers, i.e., granule cell axons innervating distal PC dendrites. Although developmental process of CF mono-innervation and its defects in mutant and experimental animal models have been extensively studied by electrophysiological techniques, relevant morphological information had been poorly understood, because of the lack of neuroanatomical methods to distinguish CFs of different neuronal origins. Soon after the identification of type 2 vesicular glutamate transporter (VGluT2) that selectively detects CF terminals in the molecular layer, we developed a novel method of combined anterograde tracer labeling and VGluT2 immunohistochemistry. This method enables us to identify the mode (mono-innervation vs. multiple innervation) of CF innervation and the site of multiple innervation. Since then, we have applied this method to various kinds of gene-manipulated mice manifesting ataxia and other cerebellar phenotypes. In this review, we summarize experimental procedures for the combined tracer/VGluT2 labeling method, and then introduce what we learned with this method when applied to studies on the role of GluRס2 and $\mathrm{Ca}_{v} 2.1$ in CF mono-innervation. This method has provided informative anatomical correlates to electrophysiological data and vice versa, and will extend our knowledge on the molecular and cellular mechanisms for development, plasticity, degeneration, and repair of the CF-PC projection system. 


\section{Introduction}

Cerebellar Purkinje cells (PCs) are innervated by two excitatory afferents: climbing fibers (CFs) originating from the inferior olivary nucleus and parallel fibers (PFs) of cerebellar granule cells (Palay and Chan-Palay, 1974). Each PC is innervated by $10^{5} \sim 10^{6}$ of PFs at distal dendrites (also called spiny branchlets), while shaft or proximal dendrites are innervated by a single CF but it forms hundreds of synapses on to the innervating PCs. Accordingly, CF activity can cause strong depolarization and trigger $\mathrm{Ca}^{2+}$ influx through voltage-dependent $\mathrm{Ca}^{2+}$ channels (VDCCs) (Kano et al., 1992; Konnerth et al., 1992; Regehr and Mintz, 1994). PCs are initially innervated by multiple CFs at birth, and surplus CFs are eliminated one by one until mono-innervation by a single main CF is achieved by the end of the third postnatal week (Hashimoto and Kano, 2003; Hashimoto et al., 2009). However, innervation by multiple CFs persists into adulthood in hypogranular animal models, where PF synaptogenesis is impaired by x-ray irradiation or spontaneous gene mutation (Woodward et al., 1974; Crepel et al., 1981; Mariani, 1982; Bravin et al., 1995; Sugihara et al., 2000). These lines of experimental evidence indicate that CF mono-innervation is established by homosynaptic competition among multiple CFs and heterosynaptic competition between PFs and CFs.

Analyses using gene-manipulated mice have extended our understanding that signaling molecules expressed at PC synapses regulate PF synaptogenesis and elimination of surplus CFs, both being the essential step for CF mono-innervation. These synaptic molecules include the metabotropic glutamate receptor mGluR1 - Gq protein subunit Gaq - phospholipase Cß4 - 
protein kinasey- pathway, the $\alpha 1 \mathrm{~A}$ subunit of P/Q-type $\mathrm{Ca}^{2+}$ channels $\left(\mathrm{Ca}_{\mathrm{V}} 2.1\right)$, GluRס2, and Cbln1 (Kano et al., 1995, 1997, 1998; Kashiwabuchi et al., 1995; Offermanns et al., 1997; Ichikawa et al., 2002; Miyazaki et al., 2004; Hirai et al., 2005b). In most of these analyses, the persistence of multiple CF innervation has been determined by whole-cell recoding, which can detect the step number of CF-evoked excitatory postsynaptic currents (EPSCs) in a given PC. The sites of innervation by main and surplus CFs were further estimated by comparing the waveform of CF-EPSCs, such as the amplitude, rise time, and decay time. In the course of these studies, electrophysiological techniques solved many questions, leaving most anatomical questions unanswered. Especially, a novel neuroanatomical method visualizing the mode of CF innervation was necessary for discussing with electrophysiological findings and specifying molecular roles more in detail for the process of CF mono-innervation.

Ten years ago, type 2 vesicular glutamate transporter (VGluT2) was identified by several groups (Aihara et al., 2000; Fremeau et al., 2001; Herzog et al., 2001). Because VGluT2 is selective to CF terminals in the molecular layer (Fremeau et al., 2001; Miyazaki et al., 2003), we assumed that CFs of different neuronal origins could be distinguished, if immunohistochemical labeling for VGluT2 is combined with anterograde tracer labeling of CFs. In this review, we first describe the combined tracer/VGluT2 labeling method to visualize the mode of CF innervation, and then introduce what we have obtained with this method from our experience of its application to mutant mice lacking GluRס2 and $\mathrm{Ca}_{\mathrm{v}} 2.1$. As to functional and molecular aspects of these molecules, see other reviews (Watanabe, 2008; Mandolesi et al., 2009; Yuzaki, 2009). 


\section{Combined tracer/VGluT2 labeling method}

Anterograde tracer labeling of CFs has been widely applied as a classical neuroanatomical method to investigate the trajectory of single axons from the inferior olive to the cerebellum, mediolateral and rostrocaudal distribution of CFs in the cerebellar cortex, and branching and terminal bouton formation of CFs in the molecular layer (Sugihara et al., 1999, 2001). We employed the dorsal approach to inject anterograde tracers into the inferior olive, and combined this with VGluT2 immunohistochemical labeling.

For tracer injection, we use stereotaxic instrument (SR-5N, Narishige, Fig. 1A) and glass pipettes prepared by a puller (PC-10, Narishige). A glass pipette, filled with $2-3 \mu \mathrm{L}$ of $10 \%$ solution of biotinylated dextran amine (BDA; 3,000 molecular weight; Invitrogen) for bight-field light microscopy and electron microscopy or dextran Alexa 594 (DA-594, Invitrogen) for confocal laser scanning microscopy in phosphate-buffered saline ( $\mathrm{pH} 7.4)$, is connected with a silicone tube to a picopump (Pneumatic Picopump; World Precision Instruments, Sarasota, FL) and set to a micromanipulator (Fig. 1A, B). Under deep anesthesia by chloral hydrate (350 mg/kg of body weight, i.p.), a mouse is clamped by ear bars at external acoustic foramen, and the line between the clamping point and the maxilla is set parallel to the horizontal plane (Fig. 1C, F). After confirming no responses of anesthetized mice to tactile stimulation, the dorsal medulla is exposed by surgical opening of the posterior atlanto-occipital membrane (Fig. 1D, E). In adult mice (about $20 \mathrm{~g}$ of body weight), the glass pipette is inserted into the medulla at an angle of $58^{\circ}$ to $59^{\circ}$ to the perpendicular line, $1.00 \mathrm{~mm}$ 
lateral from the midline, and 1.70 to $1.85 \mathrm{~mm}$ deep from the surface of the medulla (Fig. 1E, F). Tracer is injected by air pressure at 20 psi with $5 \mathrm{~s}$ intervals for $1 \mathrm{~min}$, and the surgical cut is closed using instant adhesive, Aron Alpha A Sankyo (Toagosei Co., Ltd., Tokyo, Japan). After 4 days of survival, mice are transcardially perfused with $4 \%$ paraformaldehyde in $0.1 \mathrm{M}$ sodium phosphate buffer ( $\mathrm{pH}$ 7.4) for light microscopy or with the fixative containing $0.1 \%$ glutaraldehyde for electron microscopy. After sectioning on a microslicer (50 $\mu \mathrm{m}$ in thickness), BDA is visualized by overnight incubation with peroxidase-labeled streptavidin (Nichirei, Tokyo, Japan) and colored in black using 3,3'-diaminobenzidine (DAB) and cobalt. Successful injection, which can be confirmed in coronal sections through the inferior olivary nucleus (Fig. 1G), yields selective axon labeling running in the white matter and granular layer of the cerebellum (Fig. 1H) and exhibits typical branching and varicosities of CFs in the molecular layer (Fig. 1I).

Fig. 2A and $2 \mathrm{~B}$ show images by the confocal laser scanning microscopy of parasagittal cerebellar sections labeled for fluorescent tracer DA-594, VGluT2, and calbindin. Because DA-594 labels a limited number of CFs, the course and branching of a given labeled CF can be traced in the molecular layer (Fig. 2A1). When combined with immunofluorescence for calbindin, a marker molecule of PCs, DA594-labeled CFs are visualized to climb up the molecular layer by tightly associating shaft dendrites of PCs (Fig. 2A $)$. When further applying VGluT2 immunofluorescence that labels theoretically all CF terminals within the extent of antibody-accessible depths in sections, dually labeled (tracer-labeled/VGluT2-labeled) CFs (dCF) are clearly distinguished from singly 
labeled (tracer-unlabeled/VGluT2-labeled) CF terminals (sCF) (Fig. 2A $A_{3}$ ). Importantly, dCF and sCF, which thereby originate from different inferior olivary neurons, are wired to shaft dendrites of different PCs, and never intermingled at the same dendrites in wild-type mice (Fig. 2B). At the electron microscopic level, dCF and sCF can be distinguished by dual labeling by immunogold for VGluT2 and immunoperoxidase for BDA. Fig. 2C-E show two shaft dendrites, PCD-a and PCD-b. Spines protruding from PCD-a are all innervated by dCF (Fig. 2C, D), while those from PCD-b are all innervated by sCF (Fig. 2C, E).

These results indicate that CFs of different neuronal origins can be anatomically distinguished by the combined tracer/VGluT2 labeling method at both the light and electron microscopic levels. Since then, we have been applying this method to analyses of various gene-knockout $(\mathrm{KO})$ mice to address the mode of CF innervation, i.e., mono-innervation vs. multiple innervation, and the site of additional innervation by surplus CFs (Fig. 2F) (Miyazaki et al., 2004, 2006, 2010; Kakizawa et al., 2005; Tohgo et al., 2006; Ikeda et al., 2007; Uemura et al., 2007; Tomioka et al., 2008; Watanabe et al., 2008). Of these, we have most intensively analyzed the cerebella of GluRס2-KO and $\mathrm{Ca}_{\mathrm{v}} 2.1-\mathrm{KO}$ mice, both being known to manifest severe persistence of multiple CF innervation electrophysiologically and suffer from severe ataxia behaviorally (Hashimoto et al., 2001; Ichikawa et al., 2002; Miyazaki et al., 2004).

\section{Application to GluRס2-KO mice}

Although GluRס2 is a member of 18 subunits of ionotropic glutamate receptors (Araki et al., 1993; Lomeli et al., 1993), it does not function as glutamate-gated 
ion channels (Hirai et al., 2005a; Kakegawa et al., 2007a, b). Rather, GluRס2 plays an important role in the formation and maintenance of the PF-PC synapse (Guastavino et al., 1990; Kashiwabuchi et al., 1995; Kurihara et al., 1997; Lalouette et al., 2001; Takeuchi et al., 2005) through its selective expression at this synapse (Araki et al., 1993; Lomeli et al., 1993; Takayama et al., 1995; Landsend et al., 1997) and specific interaction of its $N$-terminal domain with presynaptic molecule neurexin through Cbln1 released from granule cells (Kashiwabuchi et al., 1995; Kurihara et al., 1997; Lalouette et al., 2001; Yuzaki, 2009; Matsuda et al., 2010; Uemura et al., 2010). Primary defects in GluRס2-KO mice occur in the connectivity of PF-PC synapses, as manifested by the emergence of free spines and mismatching of pre- and postsynaptic specialization (Guastavino et al., 1990; Kurihara et al., 1997; Lalouette et al., 2001). Free spines are most numerous at the distal dendritic domain innervated by PFs only and also found at the intermediate domain receiving mixed PF and CF innervation, whereas the proximal domain only innervated by CFs lacks free spines (Ichikawa et al., 2002). This suggests that free spines are generated by failed synaptic contact with PF terminals. Moreover, the loss of GluRס2 causes the persistence of multiple innervation (Kashiwabuchi et al., 1995; Hashimoto et al., 2001; Ichikawa et al., 2002).

The combined tracer/VGluT2 labeling method visualized that both dCF and SCF are distributed in basal four-fifths of the molecular layer in wild-type mice (Fig. 2A), whereas they expand their territory almost up to the pial surface in GluRס2-KO mice (Ichikawa et al., 2002; Miyazaki et al., 2010; Fig. 3A, C). This expansion of CF territory occurs due to distal extension of CFs to innervate free 
spines generated at the distal and intermediate dendritic domains (Ichikawa et al., 2002; Miyazaki et al., 2004). As climbing up along dendrites, CFs in GluRס2-KO mice often dissociate from the host dendrites and jump to adjacent dendrites (arrowheads in Fig. 3B). In such portions, the same dendrites are multiply innervated by dCF and SCF (red and green arrows in Fig. 3B). In addition, dCF innervating a small portion of distal dendrites appears abruptly in the parasagittal plane (Fig. 3C). In such cases, ectopic innervation by dCF causes multiple innervation together with sCF (Fig. 3D). Therefore, this method can clearly demonstrate that aberrant jumping and wiring of CFs on to adjacent dendrites result in multiple innervation in GluRס2-KO mice.

In addition to the main ascending branch of CFs, there is another branch termed the transverse branch. This branch is a thin motile collateral, which extends transversely (or mediolaterally) and rarely forms conventional synapses in wild-type rodents (Rossi et al., 1991; Sugihara et al., 1999; Nishiyama et al., 2007). This branch is well identified and traced when using transverse cerebellar sections. On transverse sections, PC dendrites are seen as single straight bars, main ascending branches as ladders on the dendritic bars, and transverse branches as thin horizontal fibers emitting from the ladders (Fig. 4, 5A). The combined tracer/VGluT2 labeling method is also effective in grasping phenotypic alterations of transverse branches (Miyazaki et al., 2010). In control mice, transverse branches rarely differentiate VGluT2-positive terminals (arrowheads in Fig. 4B). In GluRס2-KO mice, however, they are substantially elongated in the mediolateral extent, frequently form VGluT2-positive terminals, and innervate dendritic bars of nearby and remote PCs (red arrows in Fig. 4D). Because the 
rest of dendritic bars are mostly innervated by SCF (green arrows), aberrant wiring by transverse $\mathrm{CF}$ branches also causes multiple innervation in GluRס2-KO mice.

Therefore, this method successfully visualizes that the ablation of GluRס2 permits aberrant wiring to PC dendrites by the ascending and transverse branches of CFs. Notably, aberrant wiring causing multiple CF innervation often occurs against distal dendrites, as indicated from distal extension of CF territory (Fig. 3A, C), aberrant jumping to distal dendrites (Fig. 3B), and aberrant elongation of synapse-forming transverse branches in superficial portions of the molecular layer (Fig. 4C, D). These phenotypes collectively suggest that the primary role of GluRס2 is to ensure PF-PC synapse formation at distal dendrites, which eventually restricts $\mathrm{CF}$ innervation to proximal dendrites and suppresses multiple CF innervation at distal dendrites (Fig. 5B, left). This notion from anatomical analyses is consistent with an electrophysiological study showing that stimulation of the main CF elicits large EPSCs with a fast rise time and high $\mathrm{Ca}^{2+}$ elevation spreading throughout the dendritic tree, whereas that of surplus CFs elicit small EPSCs with a slow rise time and low $\mathrm{Ca}^{2+}$ elevation confined to local distal dendrites (Hashimoto et al., 2001).

\section{Application to $\mathrm{Ca}_{\mathrm{v}} 2.1$ mice}

Aforementioned phenotypes suggest that the two inputs to PCs are highly competitive to each other, with one input expanding its own territory at the expense of the other. If GluRס2 regulates this competition to the advantage of PFs, there should be the counter mechanisms that expand the CF territory at the 
expense of the PF territory. We assumed that the P/Q-type $\mathrm{Ca}^{2+}$ channel is one of the likely candidates, because it mediates $>90 \%$ of the total $\mathrm{Ca}^{2+}$ current density in PCs (Mintz et al., 1992, 1995; Stea et al., 1994), is high voltage-activated VDCCs requiring strong depolarization, and could play a role as an activity coincidence detector in PCs that express no GluN2 subunits of NMDA receptors (Watanabe et al., 1994; Yamada et al., 2001). To test this hypothesis, we applied the combined tracer/VGluT2 labeling to mutant mice lacking the pore-forming subunit or Cav2.1 (Miyazaki et al., 2004).

In $\mathrm{Ca}_{\mathrm{v}} 2.1-\mathrm{KO}$ mice, the territory of $\mathrm{CF}$ innervation is regressed to a basal half of the molecular layer (Fig. 3E). In most PCs, both dCF and SCF innervate the soma and proximal dendrites of the same PCs (Fig. 3F-H), indicating high frequency of multiple innervation at the proximal somatodendritic compartment. Conspicuously, surplus CFs (dCF in Fig. $3 F$ and G, sCF in Fig. $3 \mathrm{H}$ ) also innervate the basal part of proximal dendrites as well as the soma. The somatic innervation by surplus CFs is consistent with electrophysiological data showing fast kinetics in surplus CF-EPSCs (Miyazaki et al., 2004). Furthermore, dendritic translocation of surplus CFs is also parallel with low disparity of amplitudes among multiple CF-EPSCs (Hashimoto et al., 2009). In normal developmental process of CF mono-innervation, only a single main CF translocates to dendrites, whereas surplus CFs remain in the soma and subsequently eliminated (Hashimoto et al., 2009). Therefore, in $\mathrm{Ca}_{\mathrm{v}} 2.1-\mathrm{KO}$ mice, dendritic translocation of a main CF is weakened, whereas surplus CFs retain somatic innervation and further translocate to dendrites. These characteristic phenotypes suggest that $\mathrm{Ca}_{v}$ 2.1.promotes functional differentiation of multiply-innervating CFs into single 
main CF and surplus CFs to be eliminated.

Another notable phenotype in $\mathrm{Ca}_{v} 2.1-\mathrm{KO}$ mice is reciprocal expansion of the PF territory down to proximal dendrites and somata of PCs (Miyazaki et al., 2004). This is reflected in hyperspiny transformation of somatodendritic domain of PCs and ectopic PF innervation onto these spines. Such hyperspiny transformation and expanded PF innervation are also observed following surgical denervation of CFs (Sotelo et al., 1975) or CF regression following activity blockade by TTX (Bravin et al., 1999; Morando et al., 2001; Cesa et al., 2003, 2007). Thus, $\mathrm{Ca}_{\mathrm{v}} 2.1$ potently suppresses proximal expansion of the PF territory. $\mathrm{Ca}_{\mathrm{v}} 2.1$ therefore fuels both homosynaptic competition among multiple CFs and heterosynaptic competition between PFs and CFs to the advantage of the latter (Fig. 5B, right). Therefore, armed with both GluRס2 and $\mathrm{Ca}_{v} 2.1$, highly territorial patterns of PF and CF innervation are normally structured along PC dendrites, and surplus CFs are safely eliminated from distal and proximal dendrites, leading to CF mono-innervation (Fig. 5B, middle).

In conclusion, the combined tracer/VGluT2 labeling method provides informative neuroanatomical correlates to electrophysiological data, and vice versa. This will make the CF-PC projection system one of the best circuit models in neuroscience studies on the development, plasticity, degeneration, and repair. 


\section{Reference}

Aihara Y, Mashima H, Onda H, Hisano S, Kasuya H, Hori T, Yamada S, Tomura H, Yamada Y, Inoue I, Kojima I, Takeda J (2000) Molecular cloning of a novel brain-type $\mathrm{Na}(+)$-dependent inorganic phosphate cotransporter. $\mathrm{J}$ Neurochem 74:2622-2625.

Araki K, Meguro H, Kushiya E, Takayama C, Inoue Y, Mishina M (1993) Selective expression of the glutamate receptor channel delta 2 subunit in cerebellar Purkinje cells. Biochem Biophys Res Commun 197:1267-1276.

Bravin M, Rossi F, Strata P (1995) Different climbing fibres innervate separate dendritic regions of the same Purkinje cell in hypogranular cerebellum. $J$ Comp Neurol 357:395-407.

Bravin M, Morando L, Vercelli A, Rossi F, Strata P (1999) Control of spine formation by electrical activity in the adult rat cerebellum. Proc Natl Acad Sci U S A 96:1704-1709.

Cesa R, Morando L, Strata P (2003) Glutamate receptor delta2 subunit in activity-dependent heterologous synaptic competition. J Neurosci 23:2363-2370.

Cesa R, Scelfo B, Strata P (2007) Activity-dependent presynaptic and postsynaptic structural plasticity in the mature cerebellum. J Neurosci 27:4603-4611.

Crepel F, Delhaye-Bouchaud N, Dupont JL (1981) Fate of the multiple innervation of cerebellar Purkinje cells by climbing fibers in immature control, x-irradiated and hypothyroid rats. Brain Res 227:59-71. 
Fremeau RT, Jr., Troyer MD, Pahner I, Nygaard GO, Tran CH, Reimer RJ, Bellocchio EE, Fortin D, Storm-Mathisen J, Edwards RH (2001) The expression of vesicular glutamate transporters defines two classes of excitatory synapse. Neuron 31:247-260.

Guastavino JM, Sotelo C, Damez-Kinselle I (1990) Hot-foot murine mutation: behavioral effects and neuroanatomical alterations. Brain Res 523:199-210.

Hashimoto K, Ichikawa R, Takechi H, Inoue Y, Aiba A, Sakimura K, Mishina M, Hashikawa T, Konnerth A, Watanabe M, Kano M (2001) Roles of glutamate receptor delta 2 subunit (GluRdelta 2) and metabotropic glutamate receptor subtype 1 (mGluR1) in climbing fiber synapse elimination during postnatal cerebellar development. J Neurosci 21:9701-9712.

Hashimoto K, Kano M (2003) Functional differentiation of multiple climbing fiber inputs during synapse elimination in the developing cerebellum. Neuron 38:785-796.

Hashimoto K, Ichikawa R, Kitamura K, Watanabe M, Kano M (2009) Translocation of a "winner" climbing fiber to the Purkinje cell dendrite and subsequent elimination of "losers" from the soma in developing cerebellum. Neuron 63:106-118.

Herzog E, Bellenchi GC, Gras C, Bernard V, Ravassard P, Bedet C, Gasnier B, Giros B, El Mestikawy S (2001) The existence of a second vesicular glutamate transporter specifies subpopulations of glutamatergic neurons. J Neurosci 21:RC181. 
Hirai H, Miyazaki T, Kakegawa W, Matsuda S, Mishina M, Watanabe M, Yuzaki M (2005a) Rescue of abnormal phenotypes of the delta2 glutamate receptor-null mice by mutant delta2 transgenes. EMBO Rep 6:90-95.

Hirai H, Pang Z, Bao D, Miyazaki T, Li L, Miura E, Parris J, Rong Y, Watanabe M, Yuzaki M, Morgan Jl (2005b) Cbln1 is essential for synaptic integrity and plasticity in the cerebellum. Nat Neurosci 8:1534-1541.

Ichikawa R, Miyazaki T, Kano M, Hashikawa T, Tatsumi H, Sakimura K, Mishina M, Inoue Y, Watanabe M (2002) Distal extension of climbing fiber territory and multiple innervation caused by aberrant wiring to adjacent spiny branchlets in cerebellar Purkinje cells lacking glutamate receptor delta 2. J Neurosci 22:8487-8503.

Ikeda A, Miyazaki T, Kakizawa S, Okuno Y, Tsuchiya S, Myomoto A, Saito SY, Yamamoto T, Yamazaki T, lino M, Tsujimoto G, Watanabe M, Takeshima H (2007) Abnormal features in mutant cerebellar Purkinje cells lacking junctophilins. Biochem Biophys Res Commun 363:835-839.

Kakegawa W, Miyazaki T, Hirai H, Motohashi J, Mishina M, Watanabe M, Yuzaki M (2007a) Ca2+ permeability of the channel pore is not essential for the delta2 glutamate receptor to regulate synaptic plasticity and motor coordination. J Physiol 579:729-735.

Kakegawa W, Kohda K, Yuzaki M (2007b) The delta2 'ionotropic' glutamate receptor functions as a non-ionotropic receptor to control cerebellar synaptic plasticity. J Physiol 584:89-96.

Kakizawa S, Miyazaki T, Yanagihara D, lino M, Watanabe M, Kano M (2005) Maintenance of presynaptic function by AMPA receptor-mediated 
excitatory postsynaptic activity in adult brain. Proc Natl Acad Sci U S A 102:19180-19185.

Kano M, Rexhausen U, Dreessen J, Konnerth A (1992) Synaptic excitation produces a long-lasting rebound potentiation of inhibitory synaptic signals in cerebellar Purkinje cells. Nature 356:601-604.

Kano M, Hashimoto K, Chen C, Abeliovich A, Aiba A, Kurihara H, Watanabe M, Inoue Y, Tonegawa S (1995) Impaired synapse elimination during cerebellar development in PKC gamma mutant mice. Cell 83:1223-1231.

Kano M, Hashimoto K, Kurihara H, Watanabe M, Inoue Y, Aiba A, Tonegawa S (1997) Persistent multiple climbing fiber innervation of cerebellar Purkinje cells in mice lacking mGluR1. Neuron 18:71-79.

Kano M, Hashimoto K, Watanabe M, Kurihara H, Offermanns S, Jiang H, Wu Y, Jun K, Shin HS, Inoue Y, Simon MI, Wu D (1998) Phospholipase cbeta4 is specifically involved in climbing fiber synapse elimination in the developing cerebellum. Proc Natl Acad Sci U S A 95:15724-15729.

Kashiwabuchi N, Ikeda K, Araki K, Hirano T, Shibuki K, Takayama C, Inoue Y, Kutsuwada T, Yagi T, Kang Y, et al. (1995) Impairment of motor coordination, Purkinje cell synapse formation, and cerebellar long-term depression in GluR delta 2 mutant mice. Cell 81:245-252.

Konnerth A, Dreessen J, Augustine GJ (1992) Brief dendritic calcium signals initiate long-lasting synaptic depression in cerebellar Purkinje cells. Proc Natl Acad Sci U S A 89:7051-7055.

Kurihara H, Hashimoto K, Kano M, Takayama C, Sakimura K, Mishina M, Inoue Y, Watanabe M (1997) Impaired parallel fiber-->Purkinje cell synapse 
stabilization during cerebellar development of mutant mice lacking the glutamate receptor delta2 subunit. J Neurosci 17:9613-9623.

Lalouette A, Lohof A, Sotelo C, Guenet J, Mariani J (2001) Neurobiological effects of a null mutation depend on genetic context: comparison between two hotfoot alleles of the delta-2 ionotropic glutamate receptor. Neuroscience 105:443-455.

Landsend AS, Amiry-Moghaddam M, Matsubara A, Bergersen L, Usami S, Wenthold RJ, Ottersen OP (1997) Differential localization of delta glutamate receptors in the rat cerebellum: coexpression with AMPA receptors in parallel fiber-spine synapses and absence from climbing fiber-spine synapses. J Neurosci 17:834-842.

Lomeli H, Sprengel R, Laurie DJ, Kohr G, Herb A, Seeburg PH, Wisden W (1993) The rat delta-1 and delta-2 subunits extend the excitatory amino acid receptor family. FEBS Lett 315:318-322.

Mandolesi G, Cesa R, Autuori E, Strata P (2009) An orphan ionotropic glutamate receptor: the delta2 subunit. Neuroscience 158:67-77.

Mariani J (1982) Extent of multiple innervation of Purkinje cells by climbing fibers in the olivocerebellar system of weaver, reeler, and staggerer mutant mice. J Neurobiol 13:119-126.

Matsuda K, Miura E, Miyazaki T, Kakegawa W, Emi K, Narumi S, Fukazawa Y, Ito-Ishida A, Kondo T, Shigemoto R, Watanabe M, Yuzaki M (2010) Cbln1 is a ligand for an orphan glutamate receptor delta2, a bidirectional synapse organizer. Science 328:363-368.

Mintz IM, Venema VJ, Swiderek KM, Lee TD, Bean BP, Adams ME (1992) 
P-type calcium channels blocked by the spider toxin omega-Aga-IVA. Nature 355:827-829.

Mintz IM, Sabatini BL, Regehr WG (1995) Calcium control of transmitter release at a cerebellar synapse. Neuron 15:675-688.

Miyazaki T, Fukaya M, Shimizu H, Watanabe M (2003) Subtype switching of vesicular glutamate transporters at parallel fibre-Purkinje cell synapses in developing mouse cerebellum. Eur J Neurosci 17:2563-2572.

Miyazaki T, Hashimoto K, Shin HS, Kano M, Watanabe M (2004) P/Q-type Ca2+ channel alpha1A regulates synaptic competition on developing cerebellar Purkinje cells. J Neurosci 24:1734-1743.

Miyazaki T, Hashimoto K, Uda A, Sakagami H, Nakamura Y, Saito SY, Nishi M, Kume H, Tohgo A, Kaneko I, Kondo H, Fukunaga K, Kano M, Watanabe M, Takeshima H (2006) Disturbance of cerebellar synaptic maturation in mutant mice lacking BSRPs, a novel brain-specific receptor-like protein family. FEBS Lett 580:4057-4064.

Miyazaki T, Yamasaki M, Takeuchi T, Sakimura K, Mishina M, Watanabe M (2010) Ablation of glutamate receptor GluRס2 in adult Purkinje cells causes multiple innervation of climbing fibers by inducing aberrant invasion to parallel fiber innervation territory. J Neurosci in press.

Morando L, Cesa R, Rasetti R, Harvey R, Strata P (2001) Role of glutamate delta -2 receptors in activity-dependent competition between heterologous afferent fibers. Proc Natl Acad Sci U S A 98:9954-9959.

Nishiyama H, Fukaya M, Watanabe M, Linden DJ (2007) Axonal motility and its modulation by activity are branch-type specific in the intact adult 
cerebellum. Neuron 56:472-487.

Offermanns S, Hashimoto K, Watanabe M, Sun W, Kurihara H, Thompson RF, Inoue Y, Kano M, Simon Ml (1997) Impaired motor coordination and persistent multiple climbing fiber innervation of cerebellar Purkinje cells in mice lacking Galphaq. Proc Natl Acad Sci U S A 94:14089-14094.

Palay S, Chan-Palay V (1974) Cerebellar cortex: Cytology and organization. New York: Springer:pp 63-69, 242-287.

Regehr WG, Mintz IM (1994) Participation of multiple calcium channel types in transmission at single climbing fiber to Purkinje cell synapses. Neuron 12:605-613.

Rossi F, van der Want JJ, Wiklund L, Strata P (1991) Reinnervation of cerebellar Purkinje cells by climbing fibres surviving a subtotal lesion of the inferior olive in the adult rat. II. Synaptic organization on reinnervated Purkinje cells. J Comp Neurol 308:536-554.

Sotelo C, Hillman DE, Zamora AJ, Llinas R (1975) Climbing fiber deafferentation: its action on Purkinje cell dendritic spines. Brain Res 98:574-581.

Stea A, Tomlinson WJ, Soong TW, Bourinet E, Dubel SJ, Vincent SR, Snutch TP (1994) Localization and functional properties of a rat brain alpha $1 \mathrm{~A}$ calcium channel reflect similarities to neuronal Q- and P-type channels. Proc Natl Acad Sci U S A 91:10576-10580.

Sugihara I, Wu H, Shinoda Y (1999) Morphology of single olivocerebellar axons labeled with biotinylated dextran amine in the rat. J Comp Neurol 414:131-148.

Sugihara I, Bailly Y, Mariani J (2000) Olivocerebellar climbing fibers in the 
granuloprival cerebellum: morphological study of individual axonal projections in the X-irradiated rat. J Neurosci 20:3745-3760.

Sugihara I, Wu HS, Shinoda Y (2001) The entire trajectories of single olivocerebellar axons in the cerebellar cortex and their contribution to Cerebellar compartmentalization. J Neurosci 21:7715-7723.

Takayama C, Nakagawa S, Watanabe M, Mishina M, Inoue Y (1995) Light- and electron-microscopic localization of the glutamate receptor channel delta 2 subunit in the mouse Purkinje cell. Neurosci Lett 188:89-92.

Takeuchi T, Miyazaki T, Watanabe M, Mori H, Sakimura K, Mishina M (2005) Control of synaptic connection by glutamate receptor delta2 in the adult cerebellum. J Neurosci 25:2146-2156.

Tohgo A, Eiraku M, Miyazaki T, Miura E, Kawaguchi SY, Nishi M, Watanabe M, Hirano T, Kengaku M, Takeshima H (2006) Impaired cerebellar functions in mutant mice lacking DNER. Mol Cell Neurosci 31:326-333.

Tomioka Y, Miyazaki T, Taharaguchi S, Yoshino S, Morimatsu M, Uede T, Ono E, Watanabe M (2008) Cerebellar pathology in transgenic mice expressing the pseudorabies virus immediate-early protein IE180. Eur J Neurosci $27: 2115-2132$

Uemura T, Kakizawa S, Yamasaki M, Sakimura K, Watanabe M, lino M, Mishina M (2007) Regulation of long-term depression and climbing fiber territory by glutamate receptor delta2 at parallel fiber synapses through its C-terminal domain in cerebellar Purkinje cells. $\mathrm{J}$ Neurosci $27: 12096-12108$.

Uemura T, Lee SJ, Yasumura M, Takeuchi T, Yoshida T, Ra M, Taguchi R, 
Sakimura K, Mishina M (2010) Trans-synaptic interaction of GluRdelta2 and Neurexin through Cbln1 mediates synapse formation in the cerebellum. Cell 141:1068-1079.

Watanabe F, Miyazaki T, Takeuchi T, Fukaya M, Nomura T, Noguchi S, Mori H, Sakimura K, Watanabe M, Mishina M (2008) Effects of FAK ablation on cerebellar foliation, Bergmann glia positioning and climbing fiber territory on Purkinje cells. Eur J Neurosci 27:836-854.

Watanabe M (2008) Molecular mechanisms governing competitive synaptic wiring in cerebellar Purkinje cells. Tohoku J Exp Med 214:175-190.

Watanabe M, Mishina M, Inoue Y (1994) Distinct spatiotemporal expressions of five NMDA receptor channel subunit mRNAs in the cerebellum. J Comp Neurol 343:513-519.

Woodward DJ, Hoffer BJ, Altman J (1974) Physiological and pharmacological properties of Purkinje cells in rat cerebellum degranulated by postnatal x-irradiation. J Neurobiol 5:283-304.

Yamada K, Fukaya M, Shimizu H, Sakimura K, Watanabe M (2001) NMDA receptor subunits GluRepsilon1, GluRepsilon3 and GluRzeta1 are enriched at the mossy fibre-granule cell synapse in the adult mouse cerebellum. Eur J Neurosci 13:2025-2036.

Yuzaki M (2009) New (but old) molecules regulating synapse integrity and plasticity: Cbln1 and the delta2 glutamate receptor. Neuroscience 162:633-643. 


\section{Figure legends}

Figure1. Anterograde tracer labeling of climbing fibers. (A) An overview of a stereotaxic instrument for tracer injection. (B) A tip of glass pipette filed with tracer solution. (C) A mouse clamped by ear bars and opening of the dorsal medulla (boxed region). (D) An insertion of glass pipette into the medulla. (E) A cartoon indicating the injection point (red cross) of the medulla. A broken line indicates the midline of the medulla. (F) A cartoon indicating the angle of a micromanipulator. Dotted circle indicates clamping point by ear bars. The line between the clamping point and the maxilla is set parallel to the horizontal plane (dotted line). P, perpendicular line. h, horizontal bar of the stereotaxic instrument. (G) Injection site of BDA in a coronal medulla section. BDA is visualized with diaminobenzidine (DAB) in the right inferior olive. (H) A BDA-labeled cerebellar section. BDA is visualized with DAB and cobalt. (I) A typical view of BDA-labeled CF in the molecular layer. Scale bars: $G, H, 500 \mu \mathrm{m} ; \mathrm{I}, 50 \mu \mathrm{m}$.

Figure 2. Combined tracer/VGluT2 labeling method. (A, B) Triple fluorescent labeling for calbindin $\left(A_{2}\right.$, green, $A_{3}$, blue $)$, VGluT2 $\left(A_{3}\right.$, green) and anterorade tracer DA-594 (A, red). In B, two dendrites PCD-a and PCD-b are enlarged from a boxed region of A. PCD-a is innervated by dually labeled (tracer-labeled/VGluT2-labeled) CFs (dCF), while PCD-b is innervated by singly labeled (tracer-unlabeled/VGluT2-labeled) CFs (sCF). (C-E) Double immunoelectron microscopy for BDA (diffuse DAB precipitates) and VGluT2 (metal particles). PCD-a (pseudocolored in brown) is innervated by dually labeled (tracer-labeled/VGluT2-labeled) CF (dCF), while PCD-b (green) is 
innervated by singly labeled (tracer-unlabeled/VGluT2-labeled) CF (sCF). Asterisks indicate two spines, which protrude from PCD-a or PCD-b (arrowheads), respectively and innervated by dCF or SCF, respectively. Boxed regions in $C$ are enlarged in $D$ and $E$. (F) A Cartoon showing anatomical patterns of CF mono-innervation (upper) and multiple innervation (lower) as judging from the combined tracer/VGluT2 labeling method. Scale bars, A, $20 \mu \mathrm{m} ; \mathrm{B}, 10 \mu \mathrm{m} ; \mathrm{C}$, $1 \mu \mathrm{m} ; \mathrm{D}, \mathrm{E}, 500 \mathrm{~nm}$.

Figure 3. Combined tracer/VGluT2 labeling method applied to parasagittal sections of GluRס2-knockout (KO, A-D) and $\mathrm{Ca}_{\mathrm{v}} 2.1-\mathrm{KO}(\mathrm{E}-\mathrm{H})$ mice. All images are subjected to triple fluorescent labeling for calbindin (blue), VGluT2 (green) and DA-594. Boxed regions in A, C, and $E$ are enlarged or separated in $B, D$ and F. Arrowheads in B indicate a tracer-labeled/VGluT2-labeled dCF, which jumps to the adjacent dendrite. Red or green arrows inidicate CF terminals of DA-594-labeled dCF or DA-594-unlabeled sCFs, respectively. Scale bars, A, C, E, $20 \mu \mathrm{m} ; \mathrm{B}, \mathrm{D}, \mathrm{F}, \mathrm{G}, \mathrm{H}, 10 \mu \mathrm{m}$.

Figure 4. Combined tracer/VGluT2 labeling method applied to transverse sections of control (A, B) and GluRס2-KO (C, D) mice. Triple fluorescent labeling (see a legend of Figure 3). Boxed regions in A and C are enlarged in B and D, respectively. Arrows indicate transverse branches of CFs. Arrowheads indicate VGluT2-negative transverse branches in control mice. Red arrows in D indicate DA-594-labeled transverse branches (dCF) in GluRס2-KO mice, which carry VGluT2-positive terminals and wire to distal dendrites innervated by 
DA-594-unlabeled sCFs (green arrows). Scale bars, A, C, $20 \mu \mathrm{m} ; \mathrm{B}, \mathrm{D}, \mathrm{E}, 10$ $\mu \mathrm{m}$.

Figure 5. Schematic drawings illustrating phenotypic changes in the mode of CF innervation in PCs. (A) CF-PC innervation in control (upper) and GluRס2-KO mice (lower) in the parasagittal (left) and transverse plane (right). In control mice, ascending axons of CFs keeps mono-innervation to the innervating PC, while transverse branches show no synapse formation to nearby PCs. In GluRס2-KO mice, both ascending axons and transverse branches exhibit aberrant wiring to nearby and remote PCs, causing multiple CF innervation. (B) Reciprocal

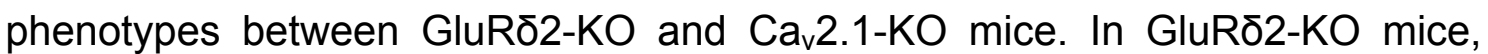
innervation by PF at distal dendrites is impaired, whereas CF innervation extends distally and causes multiple CF innervation at distal dendrites.In $\mathrm{Ca}_{\mathrm{v}} 2.1-\mathrm{KO}$ mice, on the contrary, PF territory expands down to proximal dendrites and somata, whereas CF innervation regresses proximally and causes multiple CF innervation at the proximal somatodendritic compartment. This figure is modified from Watanabe (2008). 

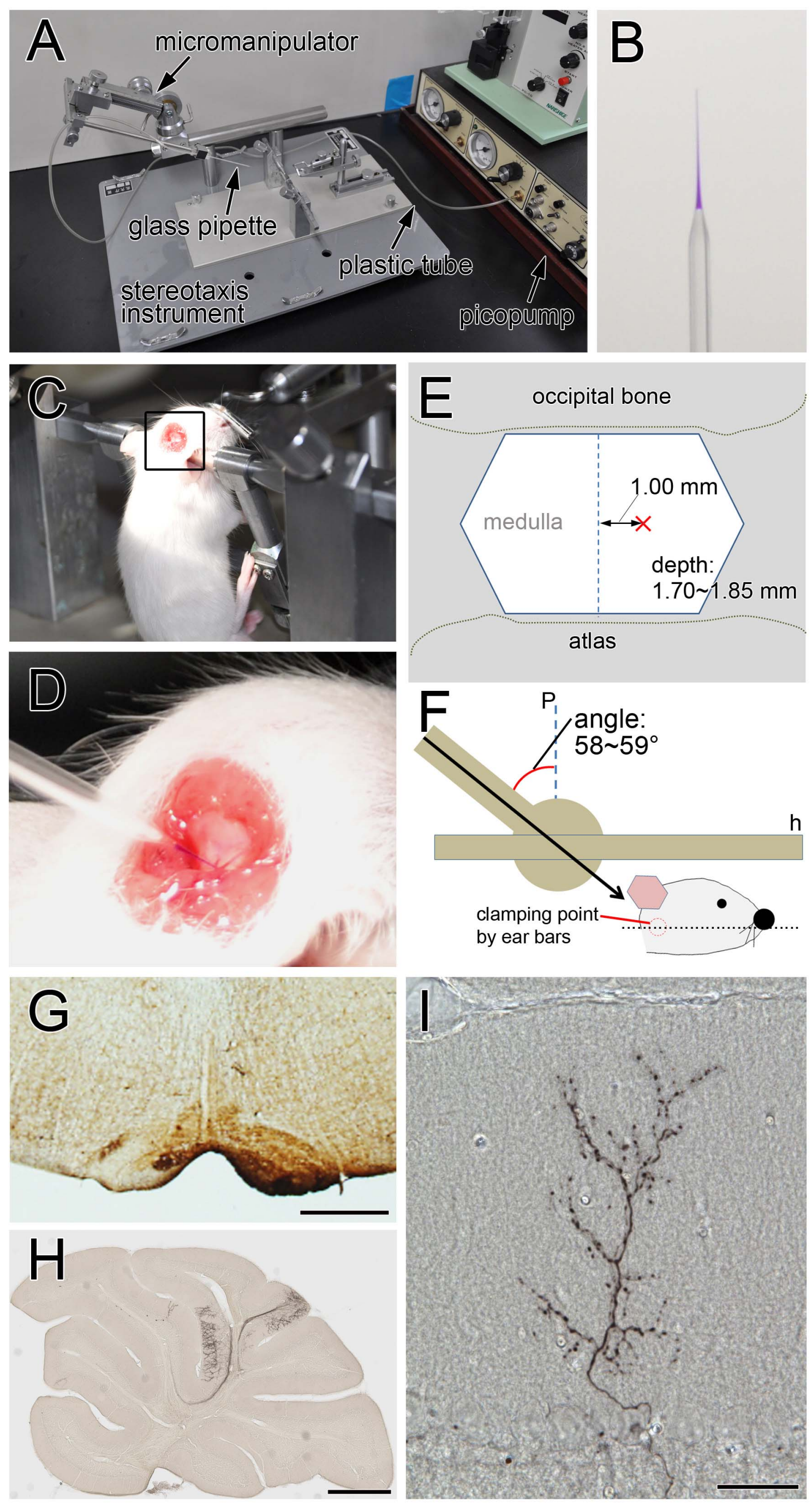

Miyazaki et al., Fig.1 


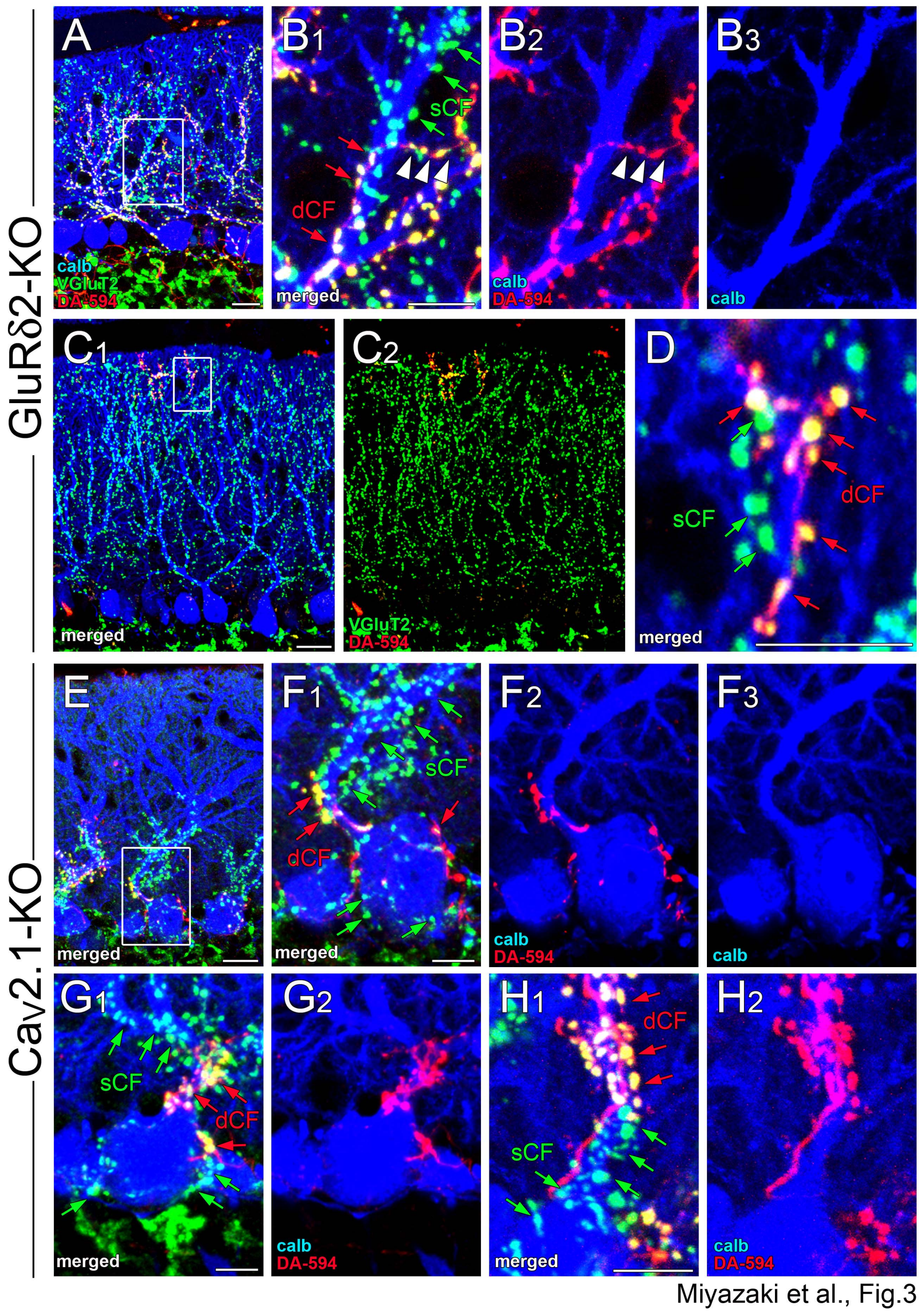



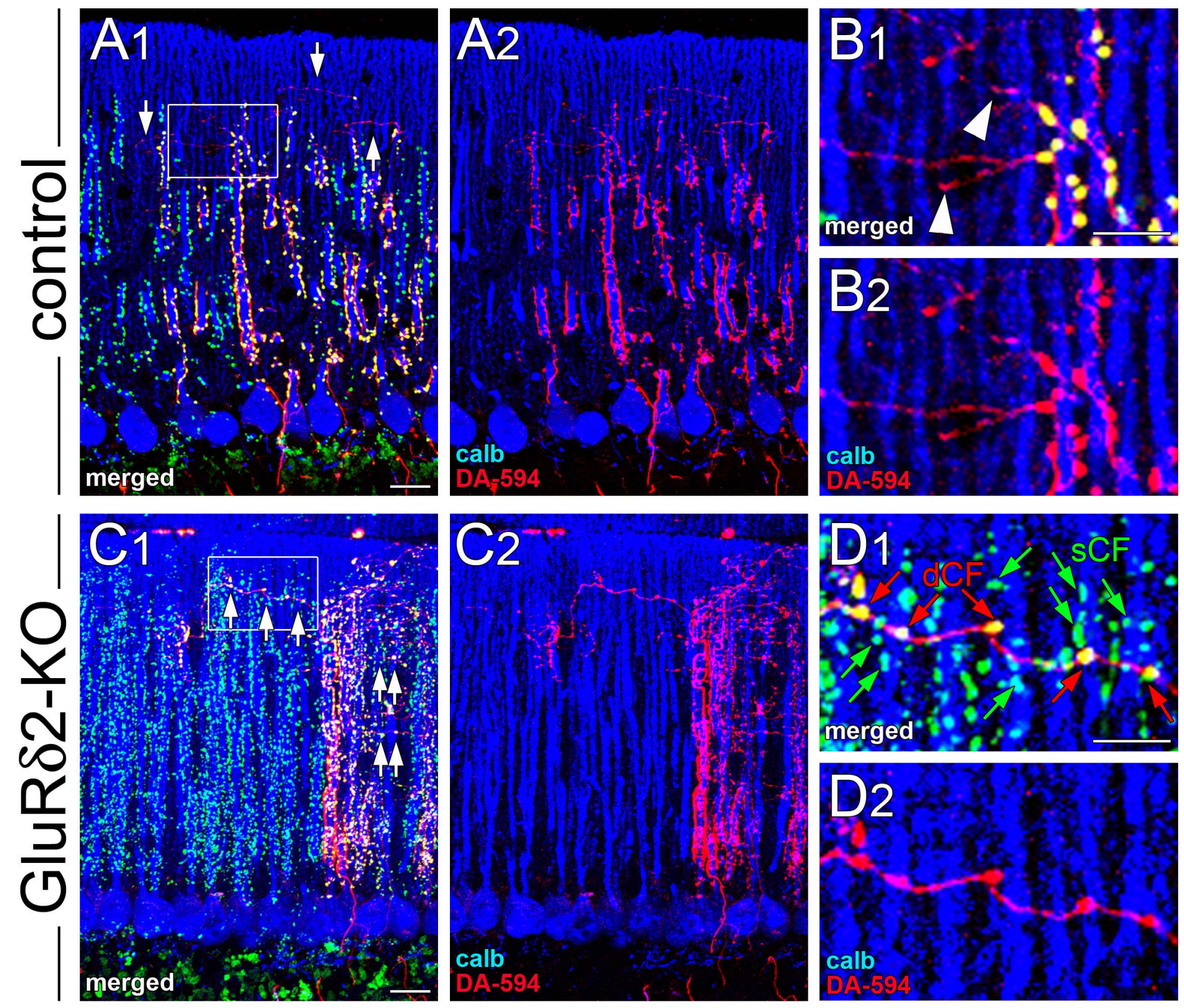

calb

DA-594
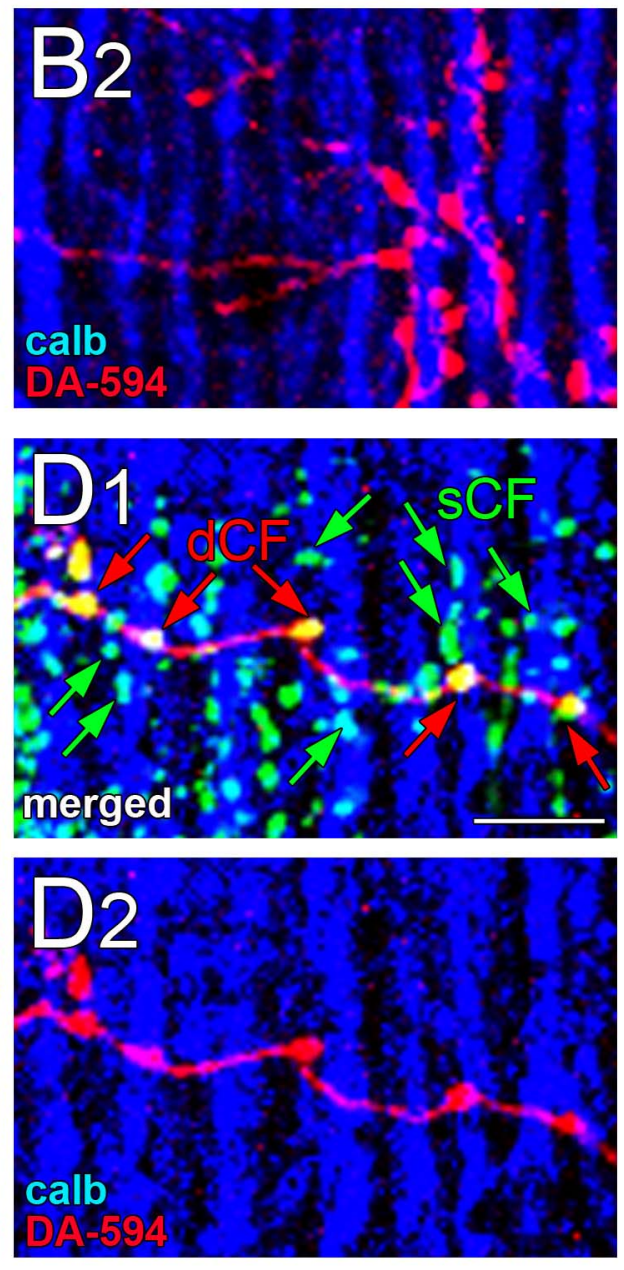

Miyazaki et al., Fig. 4 

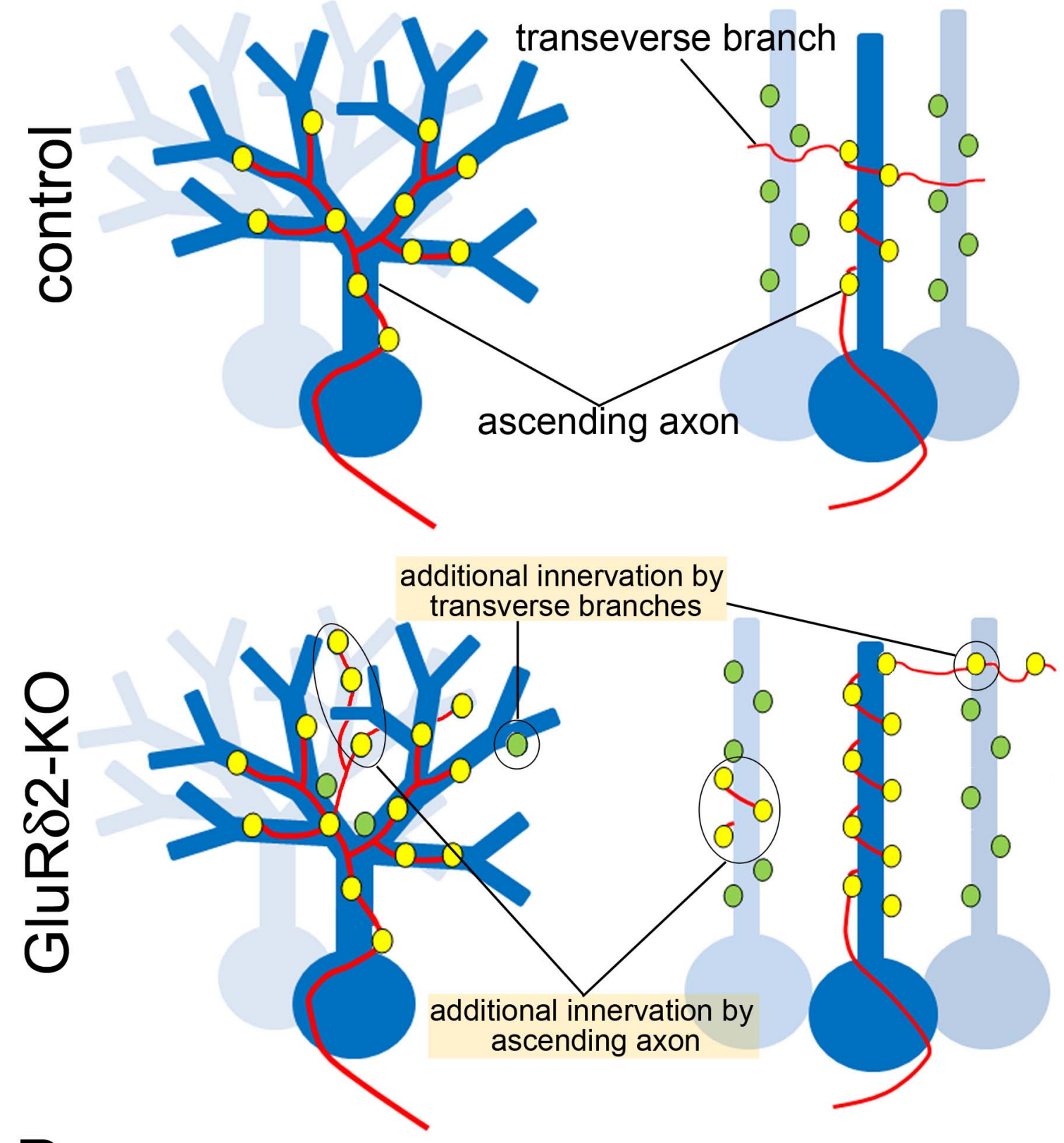

B

GluR $22 \mathrm{KO} \quad$ wild-type Cav2.1 KO

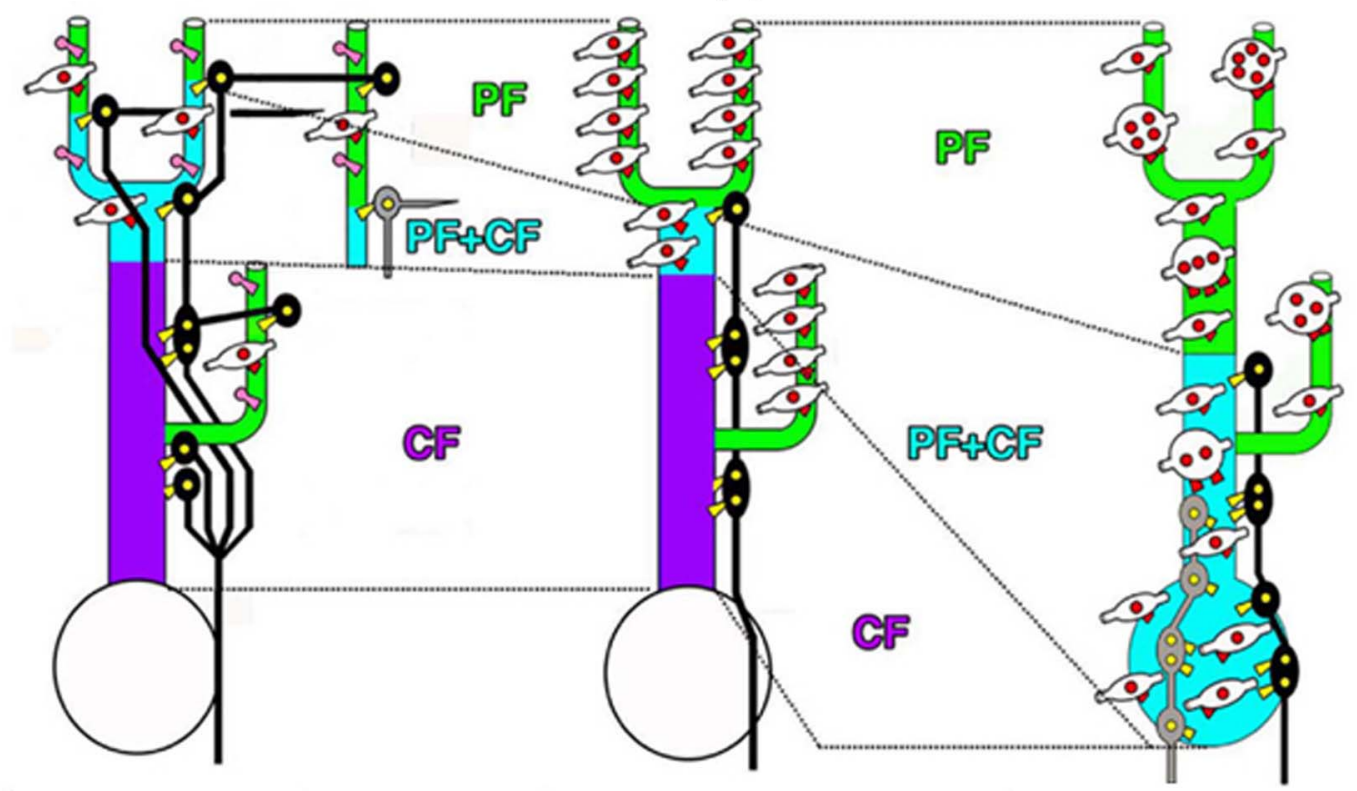

Miyazaki et al., Fig. 5 